\title{
Oxidized Low Density Lipoproteins Cause Contraction and Inhibit Endothelium-dependent Relaxation in the Pig Coronary Artery
}

\author{
Bernd C. Simon, Leslie D. Cunningham, and Richard A. Cohen \\ Peripheral Vascular Section, Robert Dawson Evans Memorial Department of Clinical Research, \\ Boston University Medical Center, Boston, Massachusetts 02118
}

\begin{abstract}
The direct vasoactive effects of native and oxidatively modified low density lipoproteins as well as their effects on endothelium-dependent relaxations to 5-hydroxytryptamine were studied in isolated rings of pig right coronary artery. Slowly developing contractions were caused by native low density lipoproteins $(100 \mu \mathrm{g}$ protein/ml). The contractions were more pronounced in the absence than in the presence of the trace metal chelator, EDTA, and coincided with the formation of lipid peroxides during the response. The lipophilic antioxidant, butylated hydroxytoluene, prevented the oxidation of, and contraction to, native low density lipoproteins. Low density lipoproteins oxidized by exposure to copper contracted coronary arteries more rapidly with a threshold of only $1 \mu \mathrm{g}$ protein $/ \mathrm{ml}$, but with a similar maximal contraction at $100 \mu \mathrm{g}$ protein $/ \mathrm{ml}$. Superoxide dismutase inhibited the contraction to native low density lipoproteins, but not to oxidized low density lipoproteins. Catalase blocked contractions to both native and oxidized low density lipoproteins. Contractions to oxidized low density lipoproteins were unaffected by indomethacin, but were abolished by removal of the endothelium or by inhibitors of endothelium-derived relaxing factor. Oxidized low density lipoproteins but not native low density lipoproteins inhibited endothelium-dependent relaxations to 5-hydroxytryptamine. Thus, oxidized low density lipoproteins cause endothelium-dependent coronary artery contractions which are mediated by a hydroperoxide. Contractions to native low density lipoproteins are due to their oxidation in the organ chamber by the superoxide anion radical. Oxidized, but not native, low density lipoproteins impair normal endothelial cell vasodilator function in vitro. Oxidized low density lipoproteins, important in the pathogenesis of atherosclerosis, may directly contribute to the increased risk of vasospasm seen in hypercholesterolemia and atherosclerosis. (J. Clin. Invest. 1990. 86:75-79.) Key words: endothelium • low density lipoproteins • oxidation • vasospasm • coronary artery
\end{abstract}

\section{Introduction}

Coronary artery spasm may account for a variety of clinical syndromes such as variant angina, acute myocardial infarc-

Address correspondence to Dr. Richard A. Cohen, E411, University Hospital, 88 E. Newton Street, Boston, MA 02118.

Received for publication 27 June 1989 and in revised form 5 February 1990

J. Clin. Invest.

(c) The American Society for Clinical Investigation, Inc

0021-9738/90/07/0075/05 \$2.00

Volume 86, July 1990, 75-79 tion, and sudden cardiac death $(1,2)$. The mechanisms of vasospasm however are not entirely clear. Atherosclerosis and hypercholesterolemia have been implicated in the pathogenesis of vasospasm and a local hyperreactivity of the coronary artery may be involved. A reduced release of endothelium-derived relaxing factor(s) (EDRF) ${ }^{1}$ may play an important role. In atherosclerotic vessels or those exposed to hypercholesterolemia, endothelium-dependent relaxations to several agonists are inhibited and contractions may be augmented (3-7).

LDLs, which are the major carriers of cholesterol in the blood, are known to be of primary importance in the development of coronary atherosclerosis, and recently it has been reported that in vitro exposure of rabbit aorta and pig coronary arteries to high concentrations of human LDL inhibited endothelium-dependent relaxations $(8,9)$. It was concluded that abnormal reactivity of atherosclerotic and hypercholesterolemic blood vessels could result from direct interactions of LDL with the endothelium.

LDL is oxidatively modified when incubated in vitro with three major cell types in the vascular wall: endothelial cells, vascular smooth muscle cells, and macrophages (10-13). This modification involves peroxidation of lipids measured as thiobarbituric acid reactive substances (TBARS) $(14,15)$ and is accompanied by a number of other changes in LDL. LDL particles show an increased negative charge causing higher electrophoretic mobility (10), increased density (10), formation of lysophosphatidylcholine (16), and a new configuration of the apoprotein $B$ which leads to its recognition by the acetyl-LDL receptor $(10,17)$. Oxidized LDL (ox-LDL) is rapidly taken up by macrophages, thus transforming these cells into foam cells, one of the earliest signs of atherosclerosis $(10,11$, 18). Recent studies suggest that oxidation of LDL occurs in vivo (19-21), and oxidatively modified LDL has been detected in atherosclerotic lesions of the rabbit and man (19).

It is not known if native LDL ( $\mathrm{n}-\mathrm{LDL}$ ) or ox-LDL have direct vasoactive properties, which may contribute to abnormal vascular reactivity during hypercholesterolemia and atherosclerosis. The role of ox-LDL in impaired endothelium-dependent relaxation under these conditions has also not yet been determined. The purpose of this study was therefore to determine possible direct vasoactive effects of $\mathrm{n}-\mathrm{LDL}$ and oxLDL as well as their effects on endothelium-dependent relaxation in pig coronary arteries.

\section{Methods}

The right coronary artery was dissected from the heart of domestic pigs killed by exsanguination after anesthesia with ketamine $(20 \mathrm{mg} / \mathrm{kg}$

1. Abbreviations used in this paper: BHT, butylated hydroxytoluene; EDRF, endothelium-derived relaxing factor(s); 5-HT, 5-hydroxytryptamine; MDA, malondialdehyde; n-LDL, native LDL; ox-LDL, oxidized LDL; PSS, physiological salt solution; TBARS, thiobarbituric acid reactive substances. 
i.m.), acepromazine ( $0.8 \mathrm{mg} / \mathrm{kg}$ i.m.), and chloralose ( $75 \mathrm{mg} / \mathrm{kg}$ i.v.), and anticoagulation with sodium heparin (100 U/kg i.v.).

Organ chamber experiments. Rings of artery $(6 \mathrm{~mm}$ long) were suspended from strain gauges for measurement of isometric circum ferential force. The rings were placed in organ chambers filled with 7 $\mathrm{ml}$ of physiological salt solution (PSS) of the following millimolar composition: $\mathrm{NaCl} 118.3, \mathrm{KCl} 4.7, \mathrm{MgSO}_{4} \mathbf{0 . 6}, \mathrm{KH}_{2} \mathrm{PO}_{4} 1.2, \mathrm{CaCl} 2.5$, $\mathrm{NaHCO}_{3} 25$, Ca-EDTA 0.026, and glucose 11.0. The solution was maintained at $37^{\circ} \mathrm{C}$ and gassed with $20 \% \mathrm{O}_{2} / 5 \% \mathrm{CO}_{2} / 75 \% \mathrm{~N}_{2}$. In some rings the endothelium was removed by inserting a stainless steel wire into the lumen and gently rolling the ring on wetted filter paper. The presence or absence of endothelial function was later confirmed by the presence or absence of relaxation caused by the endothelium-dependent vasodilator, bradykinin. The rings were progressively stretched over $1 \mathrm{~h}$ to the optimal tension for contraction, previously determined to be $12 \mathrm{~g}(22)$. To measure relaxation or contraction caused by $n-L D L$ and ox-LDL, rings $(n=71)$ were contracted with the thromboxane $A_{2}$ mimetic U46619 to $8.6 \pm 0.3 \mathrm{~g}, 35 \pm 2 \%$ of their maximal potassium-induced contraction which averaged $24 \pm 1 \mathrm{~g}$. In some cases similar tone was provided by potassium. When the U46619-induced contraction stabilized, $\mathrm{n}$-LDL or ox-LDL was added. Inhibitors were added $30 \mathrm{~min}$ before $\mathrm{LDL}$. Indomethacin $\left(10^{-5} \mathrm{M}\right)$, SOD $(120 \mathrm{U} / \mathrm{ml})$, and catalase $(1,200 \mathrm{U} / \mathrm{ml})$ did not significantly alter the contraction caused by $\mathrm{U} 46619(8.1 \pm 0.7 \mathrm{~g}, n=6 ; 7.7 \pm 0.6 \mathrm{~g}, n=7$; and $7.1 \pm 1.1 \mathrm{~g}, n=9$, respectively). Methylene blue and LY83583 increased the U46619-induced tone from $7.7 \pm 0.6 \mathrm{~g}(n=11)$ to $10.3 \pm 1.0 \mathrm{~g}(n=6)$ and $10.6 \pm 1.8$ $\mathrm{g}(n=5)$ which was statistically significant only for methylene blue.

Pilot experiments revealed that $\mathrm{n}-\mathrm{LDL}$ caused slowly developing contractions that reached a plateau after $\sim 1 \mathrm{~h}$, whereas ox-LDL caused immediate contractions. The comparison between these responses suggested that the response to $\mathrm{n}-\mathrm{LDL}$ may be due to its oxidation in the organ chamber during the experiment. $n$-LDL responses were therefore studied under different oxidizing conditions with simultaneous measurement of its degree of oxidation by removing $1 \mathrm{ml}$ of the chamber solution after the response to n-LDL reached a plateau for measurement of lipid peroxides. To prevent foaming Antifoam B (10 ppm), containing nonionic emulsifiers, was added to the organ chamber before addition of LDL. A possible influence of the antifoaming solution on the physical integrity of LDL was excluded by agarose gel electrophoresis of LDL incubated in the organ chamber for $1 \mathrm{~h}$ with antifoaming solution $(50 \mathrm{ppm})$.

To determine the effects of LDL on endothelium-dependent relaxations to 5-hydroxytryptamine (5-HT) (7) rings were contracted with U46619. After contractions stabilized, n-LDL or ox-LDL ( $100 \mu \mathrm{g}$ protein $/ \mathrm{ml}$ ) were added and $10 \mathrm{~min}$ later a dose response curve to 5-HT was constructed. To block 5-HT receptors on the vascular smooth muscle, ketanserin $\left(10^{-6} \mathrm{M}\right)$ was added $30 \mathrm{~min}$ before addition of 5-HT. Relaxations are expressed as a percentage of the maximal relaxation caused by papaverine $\left(10^{-5} \mathrm{M}\right)$.

Lipoprotein preparation. LDL was isolated by sequential ultracentrifugation from citrated fresh human plasma drawn from healthy normolipemic donors. EDTA $(1 \mathrm{mg} / \mathrm{ml})$ was added to the plasma and its density was increased to 1.025 by adding solid $\mathrm{KBr}$. After centrifugation for $18 \mathrm{~h}$ at $42,000 \mathrm{rpm}, 15^{\circ} \mathrm{C}$ in an ultracentrifuge using a $55.2 \mathrm{ti}$ rotor (Beckman Instruments, Inc., Fullerton, CA), the infranatant was collected. The pooled infranatant was then adjusted to density 1.063 , centrifuged as before, and LDL $(d=1.025-1.063 \mathrm{~g} / \mathrm{ml})$ was collected from the supernatant. In some preparations, before centrifugation the lipophilic antioxidant, butylated hydroxytoluene (BHT, $20 \mu \mathrm{M}$ ), was added directly to the plasma. The purity and integrity of LDL preparations were controlled by agarose gel electrophoresis and the protein concentration of LDL was determined by the method of Lowry (23). Before each experiment, LDL was dialyzed at $4^{\circ} \mathrm{C}$ for $24 \mathrm{~h}$ against three changes of PSS gassed with $95 \% \mathrm{~N}_{2} / 5 \% \mathrm{CO}_{2}$. LDL was oxidized by exposure to $5 \mu \mathrm{M} \mathrm{CuSO}{ }_{4}$ for $20 \mathrm{~h}$ in EDTA-free $\mathrm{H}_{2} \mathrm{O}$ at room temperature followed by dialysis at $4^{\circ} \mathrm{C}$ for $24 \mathrm{~h}$ against three changes of PSS. Copper-oxidized LDL has previously been shown to be indis- tinguishable from LDL which was biologically oxidized by endothelial cells in culture (14).

Determination of lipid peroxidation. The lipid peroxide content of n-LDL and copper-oxidized LDL was measured fluorometrically as TBARS (24). LDL (100 $\mu$ g protein) was mixed with $1.5 \mathrm{ml}$ of $0.67 \%$ thiobarbituric acid and $1.5 \mathrm{ml}$ of $20 \%$ trichloroacetic acid containing 1 $\mathrm{mg} / \mathrm{ml} \mathrm{EDTA}$. After heating at $100^{\circ} \mathrm{C}$ for $30 \mathrm{~min}$, fluorescent reaction products were assayed on a spectrofluorometer with an excitation wavelength of $515 \mathrm{~nm}$ and an emission wavelength of $553 \mathrm{~nm}$. Freshly diluted tetramethoxypropane, which yields malondialdehyde (MDA), was used as a standard and results are expressed as nanomoles of MDA equivalents. Baseline values for TBARS were obtained immediately after preparation of n-LDL or ox-LDL for each experiment.

Drugs. The following pharmacological agents were used: bradykinin acetate, 5-HT creatinine sulfate, catalase (from bovine liver, $2,890 \mathrm{U} / \mathrm{mg}$ protein), SOD (from bovine erythrocytes, $3,050 \mathrm{U} / \mathrm{mg}$ protein), indomethacin, methylene blue, BHT, 2-thiobarbituric acid, Antifoam B (Sigma Chemical Co., St. Louis, MO), LY83583 (a gift from Eli Lilly Co., Indianapolis, IN), malonaldehyde bis(dimethyl acetal) (1,1,3,3-tetramethoxypropane) (Aldrich Chemical Co., Milwaukee, WI), U46619 $(9,11$,dideoxy-11 $\alpha, 9 \alpha$-epoxymethano-prostaglandin $\mathbf{F}_{2 \alpha}$ ) (The Upjohn Co., Kalamazoo, MI)

Data analysis. The data are expressed as means \pm SEM. $n$ refers to the number of different animals from which arteries were obtained for study. Statistical analysis was performed using Student's $t$ test for unpaired observations, except for dose-response curves to 5-HT, which were compared by analysis of variance. Differences were considered to be statistically significant when the $P$-value was $<0.05$.

\section{Results}

Vasoactive effects of $n-L D L$ and ox- $L D L$. In the presence of EDTA $(26 \mu \mathrm{M})$ in coronary artery rings with endothelium contracted by U46619, the addition of n-LDL (Fig. $1 A$ ) resulted in slowly developing further contractions. The threshold for contraction was at concentrations of n-LDL of 10-100 $\mu \mathrm{g}$ protein $/ \mathrm{ml}$. Contractions reached a plateau after $\sim 1 \mathrm{~h}$. oxLDL (Fig. $1 B$ ) also contracted rings with endothelium, however the response compared with n-LDL was more rapid and occurred at lower concentrations with a threshold of 0.1-1 $\mu \mathrm{g}$ protein $/ \mathrm{ml}$. The maximal contraction to ox-LDL (100 $\mu \mathrm{g}$ protein $/ \mathrm{ml})$ was significantly greater than that to $\mathrm{n}-\mathrm{LDL}(100 \mu \mathrm{g}$ protein $/ \mathrm{ml}$ ) in the presence of EDTA (Table I). Rings without endothelium did not respond significantly to either n-LDL $(-1.2 \pm 0.6 \mathrm{~g}, n=9)$ or ox-LDL $(0.0 \pm 0.9, n=6$, Fig. 1$)$. In rings contracted with potassium, ox-LDL also caused contractions, which were not significantly different from the contractions in U46619 contracted rings $(4.3 \pm 0.8 \mathrm{~g}, n=3)$.

Responses to $n-L D L$ under different oxidizing conditions. The contractions of rings with endothelium caused by $n-L D L$ were significantly larger when EDTA was omitted from the PSS (Fig. 2, Table I). Under these conditions contractions to $\mathrm{n}$-LDL $(100 \mu \mathrm{g}$ protein $/ \mathrm{ml})$ averaged $5.3 \pm 1.1 \mathrm{~g}$ (Table I) TBARS rose from a baseline value of $0.33 \pm 0.2$ to $8.2 \pm 1.6$ (nmol MDA/mg LDL protein) measured after $1 \mathrm{~h}$ when contractions had attained a plateau (Table I). In PSS with EDTA the contractions as well as the TBARS were significantly smaller than in the absence of EDTA (Fig. 2, Table I). No significant contractions were observed when LDL treated with BHT $(20 \mu \mathrm{M})$ was added to the organ chambers in the absence of EDTA (Fig. 2, Table I). There was also no significant increase in TBARS after $1 \mathrm{~h}$ incubation of BHT-treated LDL in the organ chamber (Table I). 
A

NATIVE LDL

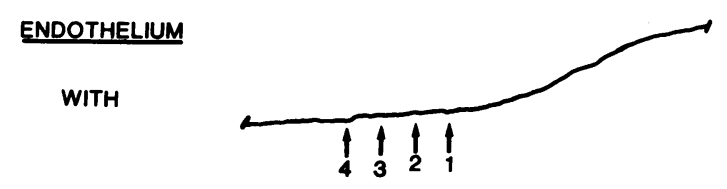

WITHOUT

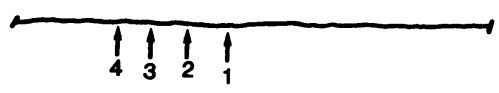

B

OXIDIZED LDL

WITH

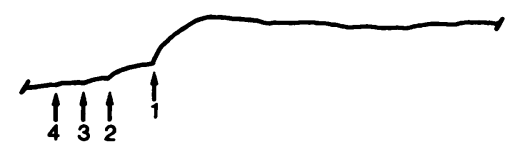

WITHOUT

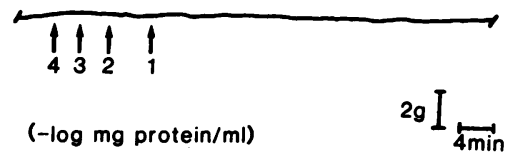

Figure 1. Original tracings of responses of pig coronary artery rings with and without endothelium to increasing concentrations of $\mathrm{n}$-LDL $(A)$ or ox-LDL $(B ; 0.1-100 \mu \mathrm{g}$ protein $/ \mathrm{ml})$. All rings were first contracted with U46619 with EDTA present. n-LDL causes a slowly developing contraction in the ring with, but not without, endothelium. ox-LDL also contracts only the ring with endothelium, but the contraction is more rapid and occurs at lower concentrations.

The maximal contractions to ox-LDL (100 $\mu \mathrm{g}$ protein $/ \mathrm{ml})$ in PSS with EDTA averaged $5.7 \pm 0.8 \mathrm{~g}$ and were not significantly different from the maximal contractions to $n-L D L$ in the absence of EDTA (Table I). ox-LDL had TBARS of $6.0 \pm 1.0$ (nmol MDA/mg protein) which was not significantly

Table I. Effect of LDL on Pig Coronary Artery Tone and Formation of Lipid Peroxides

\begin{tabular}{lcccc}
\hline & n-LDL & n-LDL & BHT-LDL & ox-LDL \\
\hline EDTA & Without & With & Without & With \\
Change in tension $(g)$ & $5.3 \pm 1.1$ & $2.2 \pm 0.5^{*}$ & $-1.1 \pm 0.8^{\ddagger}$ & $5.7 \pm 0.8$ \\
TBARS (nmole & & & & \\
MDA/mg protein) & $8.2 \pm 1.6$ & $1.0 \pm 0.1^{\ddagger}$ & $0.5 \pm 0.2^{\ddagger}$ & $6.0 \pm 1.0$ \\
$n$ & 9 & 9 & 6 & 11 \\
\hline
\end{tabular}

Values are means \pm SEM. Rings with endothelium were contracted with $\mathrm{U} 46619$ and maximal responses to $100 \mu \mathrm{g} \mathrm{LDL}$ protein/ml are indicated as either further contraction or relaxation. TBARS were measured after $1 \mathrm{~h}$ incubation in the organ chamber. Statistical comparison of data with that for $\mathrm{n}-\mathrm{LDL}$ in PSS without EDTA: * $P$ $<0.05,{ }^{\ddagger} P<0.001 . n$ indicates the number of animals from which arteries were studied.
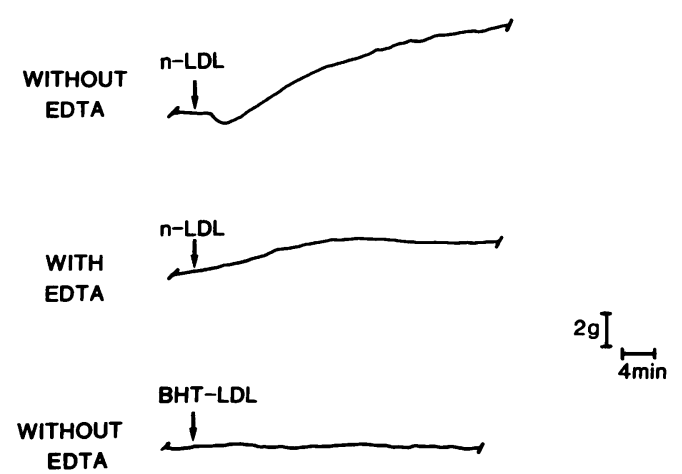

Figure 2. Original tracings of responses of coronary artery rings with endothelium to $\mathrm{n}-\mathrm{LDL}(100 \mu \mathrm{g}$ protein $/ \mathrm{ml})$ under different oxidizing conditions. All rings were first contracted with U46619. n-LDL causes a slowly developing contraction which is larger in the absence than in the presence of EDTA. BHT-LDL causes no contraction.

different from that of $\mathrm{n}$-LDL after 60 min incubation in PSS without EDTA (Table I).

Effect of inhibitors on $n-L D L$ and ox-LDL responses. Indomethacin $\left(10^{-5} \mathrm{M}\right)$ had no significant effect on the maximal contractions of coronary artery rings with endothelium induced by $n$-LDL or ox-LDL (Table II). SOD $(120 \mathrm{U} / \mathrm{ml})$ significantly inhibited the contractions to n-LDL, but did not significantly affect the contractions to ox-LDL (Table II). SOD significantly decreased TBARS formation after the addition of $\mathrm{n}$-LDL to PSS without EDTA $(2.1 \pm 0.9 \mathrm{nmol} \mathrm{MDA} / \mathrm{mg}$ LDL protein, $P<0.05)$. In the presence of catalase $(1,200 \mathrm{U} / \mathrm{ml})$ contractions to both n-LDL and ox-LDL were abolished and relaxations occurred (Table II). Methylene blue $\left(10^{-5} \mathrm{M}\right)$ or LY83583 $\left(10^{-5} \mathrm{M}\right)$ also prevented contractions caused by oxLDL and resulted in ox-LDL-induced relaxations (Table II).

Effect of $n-L D L$ and $o x-L D L$ on endothelium-dependent relaxations to $5-H T$. In the presence of ketanserin $\left(10^{-6} \mathrm{M}\right)$ the endothelium-dependent agonist, 5-HT, caused concentrationdependent relaxations. After 10 min exposure to n-LDL (100 $\mu \mathrm{g}$ protein $/ \mathrm{ml}$ ) in the presence of EDTA, the response to 5-HT

Table II. Effect of Inhibitors on $n-L D L$ and ox-LDL-induced Contractions of Pig Coronary Artery Rings with Endothelium

\begin{tabular}{lrrrr}
\hline & \multicolumn{4}{c}{ Change in tension $(g)$} \\
\cline { 2 - 5 } \multicolumn{1}{c}{ Treatment } & n-LDL & $n$ & ox-LDL & $n$ \\
\hline Control & $5.3 \pm 1.1$ & 9 & $5.7 \pm 0.8$ & 11 \\
Indomethacin $\left(10^{-5} M\right)$ & $6.4 \pm 0.5$ & 3 & $4.1 \pm 1.2$ & 3 \\
SOD $(120 \mathrm{U} / \mathrm{ml})$ & $0.7 \pm 0.9^{*}$ & 4 & $5.7 \pm 0.9$ & 3 \\
Catalase $(1,200 \mathrm{U} / \mathrm{ml})$ & $-1.4 \pm 0.5^{\ddagger}$ & 6 & $-1.7 \pm 0.6^{\ddagger}$ & 3 \\
Methylene blue $\left(10^{-5} \mathrm{M}\right)$ & & & $-5.0 \pm 1.0^{\S}$ & 6 \\
LY83583 $\left(10^{-5} \mathrm{M}\right)$ & & & $-4.3 \pm 0.8^{\S}$ & 5 \\
& & & &
\end{tabular}

Values are means $\pm S E M$. Inhibitors were added $30 \mathrm{~min}$ before the addition of n-LDL or ox-LDL. Rings were contracted with U46619 and values are the maximal change in tension in grams due to 100 $\mu \mathrm{g}$ protein/ml n-LDL or ox-LDL. Experiments with n-LDL were performed in PSS without EDTA and those with ox-LDL in PSS with EDTA. $n$ indicates the number of animals from which arteries were studied. Statistical comparisons to control data: ${ }^{*} P<0.05,{ }^{\ddagger} P$ $<0.005,{ }^{8} P<0.001$. 
A

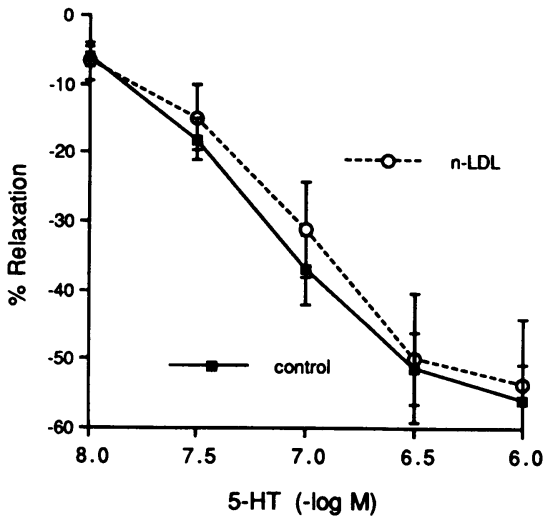

B

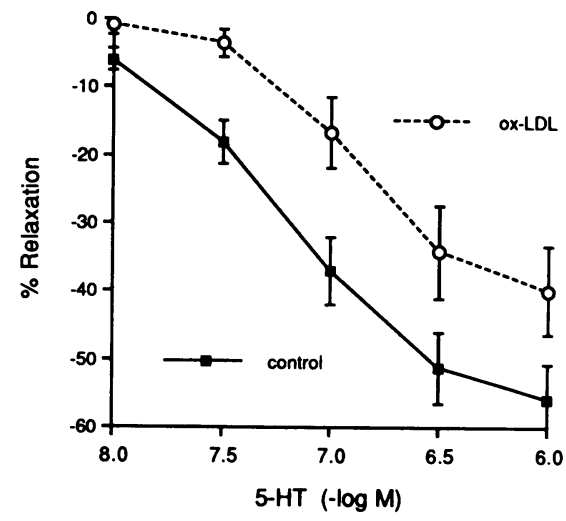

Figure 3. Effect of n-LDL $(A ; n=8)$ and ox-LDL $(B ; n=7)$ on endothelium-dependent relaxation evoked by 5 -HT in intact pig coronary artery rings. Rings in PSS with EDTA were contracted with U46619, and LDL $(100 \mu \mathrm{g} / \mathrm{ml})$ was added $10 \mathrm{~min}$ before addition of 5-HT. Relaxations are expressed as the percentage of the maximal relaxation caused by papaverine $\left(10^{-5} \mathrm{M}\right)$. ox-LDL, but not $n-L D L$, at the same protein concentration of $100 \mu \mathrm{g} / \mathrm{ml}$ caused a significant inhibition of relaxation. Comparisons were made by analysis of variance where $P<0.05$ was considered significant. was not significantly altered (Fig. 3). A 10-min exposure to ox-LDL (100 $\mu$ g protein/ml) significantly inhibited 5-HT-mediated relaxations (Fig. 3).

\section{Discussion}

This study shows that oxidatively modified LDL, which may play a key role in the pathogenesis of atherosclerosis, have direct contractile effects in pig coronary arteries. Contractions to $n-L D L$ are due to its oxidation in the organ chamber and ox-LDL, but not n-LDL, inhibit endothelium-dependent relaxations to 5-HT.

The LDL molecule is known to be unstable after its isolation from the blood. It is readily auto-oxidized in the presence of air and is highly sensitive to metal-catalyzed oxidation (25, $26)$. The aerated organ chambers to which $n-L D L$ was added therefore represent a highly oxidizing environment. Oxidation of $\mathrm{n}$-LDL under these conditions is dependent on trace metals in the buffer and the superoxide anion radical, as evidenced by the inhibitory effects of the trace metal chelator, EDTA, and SOD. Oxidation of $n-L D L$ was confirmed by measuring increased levels of lipid peroxides at the end of the experiment. Oxidation and contractions were also prevented by the lipophilic antioxidant, BHT. The oxidation of n-LDL occurring under the experimental conditions in the present study was not dependent upon the coronary artery ring as demonstrated by similar TBARS measurements when the artery was omitted from the organ chamber (unpublished observations). This study demonstrates the instability of n-LDL when used in vitro unless it is protected from oxidation.

Recent studies provide evidence that oxidation of LDL occurs in vivo (19-21). Oxidation of LDL may not occur in the circulation, because plasma inhibits the oxidation (18), but could occur in the subintima of blood vessels. ox-LDL may therefore exert its vasoconstrictor effect within the vascular wall. Atherosclerotic lesions, both in man and in the rabbit, have been shown to contain oxidatively modified LDL (19), emphasizing the relevance of our findings. The real concentrations of ox-LDL in the vascular wall are unknown, but it is not unlikely that the low concentrations of ox-LDL causing contractions in vitro $(0.1-100 \mu \mathrm{g} / \mathrm{ml})$ occur in vivo. Further studies, however, will be necessary to determine if oxidation of LDL in vivo results in coronary artery contractions.

Contractions to ox-LDL were abolished by the removal of the endothelium, suggesting several possible mechanisms for these contractile responses. The endothelium attenuates the spontaneous development of myogenic tone in the pig coronary artery, a phenomenon which is due to basal release of EDRF (22). Inhibition of the basal release of EDRF either by endothelium removal or by inhibitors of EDRF, methylene blue, LY83583, or hemoglobin (27-29) causes contractions and increases sensitivity of the pig coronary artery to contractile agents $(7,22)$. Thus, ox-LDL may act through a similar mechanism. It may block either the basal release of EDRF or interfere with its action on the vascular smooth muscle. As demonstrated by the inhibitory effect of catalase on ox-LDL responses, hydroperoxides associated with the lipid peroxides in ox-LDL are possible inhibitors of EDRF. The prevention of contraction by methylene blue and LY83583 makes it less likely that endothelium-derived vasoconstrictor substances such as endothelin (30) mediate the contractions caused by ox-LDL. Vasoconstrictor prostanoids were ruled out by the failure of the cyclooxygenase inhibitor indomethacin to block the contractions.

Preliminary studies showed that ox-LDL causes significant, but smaller, contractions of pig coronary arteries with endothelium which are not contracted with U46619 (1.1 $1 \pm 0.2$ $\mathrm{g}, n=6)$. Thus, the magnitude of contractions to ox-LDL depends upon preexisting tone which in this study was provided by the thromboxane $A_{2}$-mimetic. Since contractile responses to ox-LDL were not significantly different when artery rings were contracted with potassium, it is unlikely that contractions to ox-LDL were due to some specific interactions with U46619. Nevertheless, contractile synergism may occur in vivo between ox-LDL and vasoactive factors such as thromboxane $A_{2}$ which may be released from platelets at sites of atherosclerosis.

Endothelium-dependent relaxations to 5-HT and other agonists are impaired in coronary arteries from hypercholesterolemic or atherosclerotic pigs and man (7, 31-33). Previous studies in rabbit aorta (8) and pig coronary artery (9) showed that LDL, under conditions shown to be oxidizing in the present study, impaired endothelium-dependent relaxation. The observation that ox-LDL, but not n-LDL, inhibits the response to 5-HT suggests a role of oxidatively modified LDL in the impaired endothelium-dependent vascular relaxation observed in arteries exposed to LDL in vitro and in vivo.

In conclusion, this study demonstrates that aside from its atherogenic potential, ox-LDL, by impairing normal endothelial vasodilator function, could directly contribute to the in- 
creased risk of coronary vasospasm seen in hypercholesterolemia and atherosclerosis.

\section{Acknowledgments}

The authors wish to thank Anne Tercyak, Cheryl Oliva, and Cynthia Curry for help with lipoprotein preparation and assays and Marie Ryan for preparing the figures.

Dr. Simon was supported by a fellowship from the American Heart Association, Massachusetts Affiliate. Dr. Cohen was supported by an Established Investigator Award from the American Heart Association. The work was supported by grants HL31607 and HL38731 from the National Institutes of Health.

\section{References}

1. Prinzmetal, M., R. Kennamer, R. Merliss, T. Wada, and N. Bor. 1959. Angina pectoris I. A variant form of angina pectoris. Am. J. Med. 27:375-388.

2. Weiner, L., H. Kasparian, P. R. Duca, P. Walinsky, R. S. Gottlieb, F. Hanckel, and A. N. Brest. 1976. Spectrum of coronary arterial spasm: clinical angiographic and myocardial metabolic experience in 29 cases. Am. J. Cardiol. 38:945-955.

3. Henry, P. D., and M. Yokoyama. 1980. Supersensitivity of atherosclerotic rabbit aorta to ergonovine. Mediation by a serotonergic mechanism. J. Clin. Invest. 66:306-313.

4. Shimokawa, H., H. Tomoike, S. Nabeyama, H. Yamamoto, H. Araki, and M. Nakamura. 1983. Coronary artery spasm induced in atherosclerotic miniature swine. Science (Wash. DC). 221:560-562.

5. Heistad, D. D., M. L. Armstrong, M. L. Marcus, D. J. Piegors, and A. L. Mark. 1984. Augmented responses to vasoconstrictor stimuli in hypercholesterolemic and atherosclerotic monkeys. Circ. Res. 54:711-718.

6. Yamamoto, Y., H. Tomoike, K. Egashira, and M. Nakamura. 1987. Attenuation of endothelium-related relaxation and enhanced responsiveness of vascular smooth muscle to histamine in spastic coronary arterial segments from miniature pigs. Circ. Res. 61:772-778.

7. Cohen, R. A., K. M. Zitnay, C. C. Haudenschild, and L. D. Cunningham. 1988. Loss of selective endothelial cell vasoactive functions caused by hypercholesterolemia in pig coronary arteries. Circ. Res. 63:903-910.

8. Andrews, H. E., K. R. Bruckdorfer, R. C. Dunn, and M. Jacobs. 1987. Low density lipoproteins inhibit endothelium-dependent relaxation in rabbit aorta. Nature (Lond.). 327:237-239.

9. Cohen, R. A., and L. D. Cunningham. 1988. Low density lipoproteins inhibit endothelium-dependent relaxations caused by bradykinin in the pig coronary artery. Circulation. 78(Suppl II):183. (Abstr.)

10. Henriksen, T., E. M. Mahoney, and D. Steinberg. 1981. Enhanced macrophage degradation of low density lipoprotein previously incubated with cultured endothelial cells: recognition by receptor for acetylated low density lipoproteins. Proc. Natl. Acad. Sci. USA. 78:6499-6503.

11. Henriksen, T., E. M. Mahoney, and D. Steinberg. 1983. Enhanced macrophage degradation of biologically modified low density lipoprotein. Arteriosclerosis. 3:149-159.

12. Cathcart, M. K., D. W. Morel, and G. M. Chisolm. 1985. Monocytes and neutrophils oxidize low density lipoproteins making it cytotoxic. J. Leukocyte Biol. 38:341-350.

13. Parthasarathy, S., D. J. Printz, D. Boyd, L. Joy, and D. Steinberg. 1986. Macrophage oxidation of low density lipoprotein generates a modified form recognized by the scavenger receptor. Arteriosclerosis. 6:505-510.

14. Steinbrecher, U. P., S. Parthasarathy, D. S. Leake, J. L. Witztum, and D. Steinberg. 1984. Modification of low density lipoprotein by endothelial cells involves lipid peroxidation and degradation of low density lipoprotein phospholipids. Proc. Natl. Acad. Sci. USA. 81:3883-3887.
15. Hessler, J. R., D. W. Morel, L. J. Lewis, and G. M. Chisolm. 1983. Lipoprotein oxidation and lipoprotein-induced cytotoxicity. $A r-$ teriosclerosis. 3:215-222.

16. Heinecke, J. W., H. Rosen, and A. Chait. 1984. Iron and copper promote modification of low density lipoprotein by human arterial smooth muscle cells in culture. J. Clin. Invest. 74:1890-1894.

17. Fong, L. G., S. Parthasarathy, J. L. Witztum, and D. Steinberg. 1987. Nonenzymatic oxidative cleavage of peptide bonds in apoprotein B-100. J. Lipid. Res. 28:1466-1477.

18. Steinberg, D., S. Parthasarathy, T. E. Carew, J. C. Khoo, and J. L. Witztum. 1989. Beyond cholesterol: modifications of low density lipoprotein that increase its atherogenecity. N. Engl. J. Med. 320:915924.

19. Ylä-Herttuala, S., W. Palinski, M. E. Rosenfeld, S. Parthasarathy, T. E. Carew, S. Butler, J. L. Witztum, and D. Steinberg. 1989. Evidence for the presence of oxidatively modified low density lipoprotein in atherosclerotic lesions of rabbit and man. J. Clin. Invest. 84:1086-1095.

20. Haberland, M. E., D. Fong, and L. Cheng. 1988. Malondialdehyde-altered protein occurs in atheroma of Watanabe heritable hyperlipidemic rabbits. Science (Wash. DC). 241:215-218.

21. Palinski, W., M. E. Rosenfeld, S. Ylä-Herttuala, G. C. Gurtner, S. S. Socher, S. W. Butler, S. Parthasarathy, T. E. Carew, and D. Steinberg. 1989. Low density lipoprotein undergoes oxidative modifcation in vivo. Proc. Natl. Acad. Sci. USA. 86:1372-1376.

22. Cohen, R. A., K. M. Zitnay, R. M. Weisbrod, and B. Tesfamariam. 1988. Influence of the endothelium on tone and the response of isolated pig coronary artery to norepinephrine. J. Pharmacol. Exp. Ther. 244:550-555.

23. Lowry, O. H., N. J. Rosebrough, A. L. Farr, and R. J. Randall. 1951. Protein measurement with the Folin phenol reagent. J. Biol. Chem. 193:265-275.

24. Yagi, K. 1976. A simple fluorometric assay for lipidperoxide in blood plasma. Biochem. Med. 15:212-216.

25. Schuh, J., G. F. Fairclough, and R. H. Haschemeyer. 1978. Oxygen-mediated heterogeneity of apo-low-density lipoprotein. Proc. Natl. Acad. Sci. USA. 75:3173-3177.

26. Nichols, A. V., C. S. Rehnborg, and F. T. Lindgren. 1961. Gas chromatographic analysis of fatty acids from dialyzed lipoproteins. $J$. Lipid Res. 2:203-207.

27. Martin, W., G. M. Villani, D. Jothianandan, and R. F. Furchgott. 1985. Selective blockade of endothelium-dependent and glyceryl trinitrate-induced relaxation by hemoglobin and by methylene blue in the rabbit aorta. J. Pharmacol. Exp. Ther. 232:708-716.

28. Diamond, J. 1987. Effects of LY83583, nordihydroguaiaretic acid, and quinacrine on cyclic GMP elevation and inhibition of tension by muscarinic agonists in rabbit aorta and left atrium. Can. J. Physiol. Pharmacol. 65:1913-1917.

29. Bény, J.-L., P. C. Brunet, and V. Van der Bent. 1989. Hemoglobin causes both endothelium-dependent and endothelium-independent contraction of the pig coronary arteries, independently of an inhibition of EDRF effects. Experientia (Basel). 45:132-134.

30. Yanagisawa, M., H. Kurihara, S. Kimura, Y. Tomobe, M. Kobayashi, Y. Mitsui, Y. Yazaki, K. Goto, and T. Masaki. 1988. A novel vasoconstrictor peptide produced by vascular endothelial cells. Nature (Lond.). 332:411-415.

31. Bossaller, C., G. B. Habib, H. Yamamoto, C. Williams, S. Wells, and P. D. Henry. 1987. Impaired muscarinic endothelium-dependent relaxation and cyclic guanosine 5 '-monophosphate formation in atherosclerotic human coronary artery and rabbit aorta. J. Clin. Invest. 79:170-174.

32. Förstermann, U., A. Mügge, U. Alheid, A. Haverich, and J. C. Frolich. 1988. Selective attenuation of endothelium-mediated vasodilatation in atherosclerotic human coronary arteries. Circ. Res. 62:185-190.

33. Yamamoto, Y., H. Tomoike, K. Egashira, and M. Nakamura. 1987. Attenuation of endothelium-related relaxation and enhanced responsiveness of vascular smooth muscle histamine in spastic coronary arterial segments from miniture pigs. Circ. Res. 61:772-778. 